Incident analysis

\section{Analysis of clinical incidents: a window on the system not a search for root causes}

\section{A Vincent}

\section{It is time to pay more attention to incident analysis}

l: ncident reporting lies at the heart of many initiatives to improve patient safety. The UK National Patient Safety Agency (NPSA) ${ }^{1}$ has recently launched a national reporting and learning system following substantial piloting and testing across the National Health Service (NHS). In the USA the Agency for Healthcare Research and Quality (AHRQ) made incident reporting the centrepiece of its first patient safety funding programme, investing \$25 million in the first year into research in incident reporting systems. ${ }^{2}$ The Australian incident monitoring system has amassed a massive database of reports over 15 years. $^{3}$ New risk management and patient safety programmes-whether local or national-rely on incident reporting to provide data on the nature of safety problems and to provide indications of the causes of those problems and the likely solutions.

Incident reports by themselves, however, tell you comparatively little about causes and prevention, a fact which has long been understood in aviation. ${ }^{4}$ Reports are often brief and fragmented; they are not easily classified or pigeon holed. Making sense of them requires clinical expertise and a good understanding of the task, the context, and the many factors that may contribute to an adverse outcome. At a local level, review of records and, above all, discussions with those involved can lead to a deeper understanding of the causes of an incident. Surprisingly little attention, however-and even less funding - has been given to the key issue of incident analysis.

\section{PERSPECTIVES ON CLINICAL INCIDENTS}

A clinical scenario can be examined from a number of different perspectives, each of which may illuminate one facet of the case. Cases have, from time immemorial, been used to educate and reflect on the nature of disease. They can also be used to illustrate the process of clinical decision making, treatment options and sometimes, particularly when errors are discussed, the personal impact of incidents and mishaps. Incident analysis, for the purposes of improving the safety of health care, may encompass all of these perspectives but, critically, also includes reflection on the broader healthcare system. This process is usually known by the wholly inappropriate term "root cause analysis". ${ }^{5}$

There are a number of methods of incident investigation and analysis available in health care. In the USA the most familiar is the root cause analysis approach of the Joint Commission, an intensive process with its origins in total quality management approaches to healthcare improvement. ${ }^{6}$ The Veterans Hospital Administration has developed a highly structured system of triage questions which is being disseminated throughout their system. ${ }^{7}$ In the UK the Clinical Safety Research Unit has developed a "systems analysis" of incidents based on Reason's model and our own framework of contributory factors. ${ }^{8} 9$ A revised and updated version is now available..$^{11}$ The NPSA has developed a root cause analysis teaching programme which is an amalgam of elements of all these approaches.

\section{A WINDOW ON THE SYSTEM}

We have described our own approach to the analysis of incidents as a systems analysis rather than a root cause analysis. The term "root cause analysis", while widespread, is misleading in a number of respects. To begin with, it implies that there is a single root cause, or at least a small number. Typically, however, the picture that emerges is much more fluid and the notion of a root cause is a gross oversimplification. ${ }^{59}$ Usually there is a chain of events and a wide variety of contributory factors leading up to the eventual incident. A more important and fundamental objection to the term "root cause analysis" relates to the very purpose of the investigation. Surely the purpose is obvious? To find out what happened and what caused it. Certainly, it is necessary to find out what happened and why in order to explain to the patient, his or her family, and others involved. However, if the purpose is to achieve a safer healthcare system, then it is necessary to go further and reflect on what the incident reveals about the gaps and inadequacies in the healthcare system in which it occurred. The incident acts as a "window" on the system-hence systems analysis. Incident analysis, properly understood, is not a retrospective search for root causes but an attempt to look to the future. In a sense, the particular causes of the incident in question do not matter as they are now in the past. However, the weaknesses of the system revealed are still present and could lead to the next incident.

\section{PROSPECTIVE AND RETROSPECTIVE APPROACHES}

Prospective analyses of systems are increasingly being explored in health care on the reasonable argument that it is better to examine safety proactively and to prevent incidents before they happen. Incident analysis is usually seen as retrospective while techniques such as Failure Modes and Effects Analysis (FMEA), which examine a process of care, are seen as prospective. FMEA and related approaches are being trialled in a variety of settings and endorsed by the US Veterans Administration, UK NPSA, and others. ${ }^{12}{ }^{13}$ We might think that, as health care becomes safer, these prospective analyses will eventually supplant incident analysis. Leaving aside the fact that health care has rather a long way to go before the supply of incidents dries up, there are a number of reasons for continuing to explore individual incidents as well as examining systems prospectively.

Firstly, there is no sharp division between retrospective and prospective techniques; as argued above, the true purpose of incident analysis is to use the incident as a window onto the systemin essence, looking at current weaknesses and future potential problems. Conversely, so called "prospective analysis" relies extensively on the past experience of those involved. Probabilities and hazards assessed in FMEA are derived almost exclusively from groups of clinicians on the basis of their past experience. Techniques such as FMEA are, in addition, very expensive in terms of time and resources. ${ }^{13}$ The analysis of single incidents-whether or not they have a bad outcome-can be scaled to the time and resource available, be it 10 minutes or 10 days. ${ }^{14} \mathrm{~A}$ single incident - a story —almost always engages a clinical group and can be analysed by an individual risk manager 
or a whole clinical team. The future probably lies in a judicious application of both forms of techniques, using systems analyses of incidents to generate both enthusiasm and hypotheses as a basis for more resource intensive analyses of whole processes and systems.

A major concern with all the techniques discussed is the lack of formal testing and evaluation. The process of analysing incidents could be considered simply as a method of engaging teams in reflecting on safety; in that case, formal evaluation may not be critical. However, if we believe it could function as a more formal diagnostic technique exposing flaws in healthcare systems, then questions of inter-rater reliability and the validity of the conclusions become important. With vast funds being sunk into the research and development of reporting and tracking of incidents, it is perhaps time to pay more attention to the ultimately more important-but greatly neglected-issue of incident analysis.

Qual Saf Health Care 2004; 13:242-243.

doi: 10.1136/qshc.2004.010454

Correspondence to: Professor C A Vincent, Smith \& Nephew Foundation Professor of Clinical Safety Research, Department of

Surgical Oncology and Technology, Imperial College School of Science, Technology and Medicine, St Mary's Hospital Campus, London W2 1NY, UK; c.vincent@imperial.ac.uk

\section{REFERENCES}

National Patient Safety Agency www.npsa.nhs.uk (accessed 8 June 2004)

2 Agency for Healthcare Research and Quality. www.ahrq.gov, 2004.

3 Runciman B, Merry A, McCall Smith A. Improving patients' safety by gathering information. BMJ 2001;323:298.

4 Cook RI, Woods DD, Miller CA. A tale of two stories: contrasting views of patient safety, US National Patient Safety Foundation, 1998.

5 Vincent C. Understanding and responding to adverse events. N Engl J Med 2003;348:1051-6.
6 Spath $\mathbf{P}$, ed. Error reduction in health care: a systems approach to improving patient safety. Washington: AHA Press, 1999.

7 Stalhandske E, Bagian JP, Gosbee J. Department of Veterans Affairs patient safety program. AJIC: Am J Infection Control 2002;30:296-302

8 Vincent C, Taylor-Adams S, Stanhope N. Framework for analysing risk and safety in clinical medicine. BMJ 1998;316:1154-7.

9 Vincent C, Taylor-Adams S, Chapman EJ, et al. How to investigate and analyse clinical incidents: clinical risk unit and association of litigation and risk management protocol. $B M J$ risk management prot.

10 Clinical Safety Research Unit. www.csru.org.uk (accessed 8 June 2004).

11 Institute for Healthcare Improvement. www.ihi.org (accessed 25 June 2004).

12 DeRosier J, Stalhandske E, Bagian JP, et al. Using health care failure mode and effect analysis: the VA National Center for Patient Safety's prospective risk analysis system. Jt Comm J Qual Improv 2002;28:248-67.

13 McNally KM, Page MA, Sunderland B. Failuremode and effects analysis in improving a drug distribution system. Am J Health System Pharmacy 1997;54:171-7.

14 Frankel A, Graydon-Baker E, Neppl C, et al. Patient safety leadership walk rounds. Jt Comm J Qual Improv 2003;29:16-26.

\section{Using statistical process control to improve the quality of health care}

\section{A Mohammed}

\section{To achieve continuous quality improvement "it is not enough to do your best ..."}

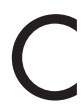
ontinuous improvement in health care and elsewhere is not a contentious issue-but the means by which this may be achieved is the subject of much debate. A key aspect of continuous improvement is the measurement, analysis, and interpretation of variation. Consider, for example, the data in table 1 which shows surgeon specific mortality rates after colorectal cancer surgery. ${ }^{1}$ Ranking the mortality rates or the adjusted hazard ratios, with or without statistical tests, invites the interpretation that some surgeons are better than others. Furthermore, since a hazard ratio of 1 is defined as neutral, surgeons with a hazard ratio above 1 are considered a hazard to their patients. So, by categorising the hazard ratio as either acceptable or unacceptable, the study concludes that "some surgeons perform less than optimal surgery; some are less competent technically than their colleagues..." To improve outcomes the next logical step is to stop the less competent surgeons from operating and transfer their patients to the more competent surgeons. Surprisingly, per- haps, there is another way of analysing these data using statistical process control (SPC) which leads to very different conclusions.

\section{BACKGROUND TO STATISTICAL PROCESS CONTROL (SPC)}

In the 1920s Walter A Shewhart, a physicist, was charged with improving
$\mathrm{HR}$, hazard ratio.

Table 1 Surgeon specific mortality rates following colorectal cancer surgery

\begin{tabular}{llll}
\hline Surgeon & No of cases & No $(\%)$ died & Case mix adjusted HR \\
\hline A & 98 & $16(16)$ & 1.10 \\
B & 66 & $8(12)$ & 1.03 \\
C & 58 & $9(16)$ & 0.87 \\
D & 52 & $7(13)$ & 1.09 \\
E & 52 & $15(29)$ & 1.09 \\
F & 46 & $5(11)$ & 0.86 \\
G & 38 & $3(8)$ & 0.86 \\
H & 37 & $11(30)$ & 1.61 \\
I & 36 & $5(14)$ & 0.91 \\
J & 34 & $7(21)$ & 1.05 \\
K & 32 & $4(13)$ & 0.59 \\
L & 21 & $2(10)$ & 0.97 \\
M & 21 & $3(14)$ & 0.79 \\
\hline
\end{tabular}

the quality of telephones in Bell Laboratories, USA. His work there won him the accolade of the "father of modern quality control". ${ }^{2}$ Shewhart developed a theory of variation ${ }^{3}$ which forms the basis of SPC. His theory is easily illustrated. Consider the first five "QSHC" signatures in fig 1. Two important observations can be made: (1) despite being produced by the same process, they show variation; and (2) the variation is controlled-it lies within certain limits. If nothing is known about the underlying process one would be justified in suggesting that the process appears to be stable. What would traditional approaches to understanding variation tell us about these signatures? The five signatures could be compared to a standard, and some would fall below the standard. A league table could be created, ranking the signatures from best to worst. A statistical test might identify one signature as significantly different from the others. These 
approaches invite punishment of the writer of the worst signature and reward for the writer of the best signature. Yet, from the point of view of the underlying process, the five signatures are similar. No signature is better or worse than the others. For improvement, the process which produced these signatures must be fundamentally changed.

Now consider the sixth signature. It is clearly different from the others. A casual look suggests that this variation must have a special cause which needs to be found and eliminated to prevent it from interacting with an otherwise stable process. In this case the sixth signature was produced with the writer using his left hand. By finding this out, a simple lesson is learned-one hand is better than the other at writing signatures.

The critical feature of Shewhart's theory of variation is that it categorises variation according to the action needed to reduce it. To reduce common cause variation one must act on the process. To reduce special cause variation one must find and act on the special cause(s). To help distinguish between these two kinds of variation Shewhart devised the premier tool of SPC-the control chart (fig 2). Control charts have three important lines. The central line is the mean or median, and the upper and lower lines are termed control limits. Data points outside the control limits (or unusual data patterns) indicate a special cause which should be found and eliminated. However, like any diagnostic tool, the guidance from the control chart is not infallible. Sometimes an outcome resulting from common cause variation is mistakenly taken to indicate a special cause. Sometimes an outcome resulting from a special cause is mistakenly attributed to common cause variation. It is impossible to reduce the frequency of both errors to zero. In the light of this, Shewhart chose to set the control limits at three sigma from the mean (or median), a level that minimised the economic consequences of both kinds of mistakes. This choice was based on a combination of statistical theory, empirical evidence, and pragmatism. ${ }^{3}$

Now, if the data in table 1 are reconsidered with the aid of a control chart, profoundly different conclusions are reached from those of the original study. All but one of the surgeons' results are consistent with common cause variation. The appropriate action to improve their results is to change

\section{qushe gsthe qushe qshe qushe aphe.}

Figure 1 Signatures.

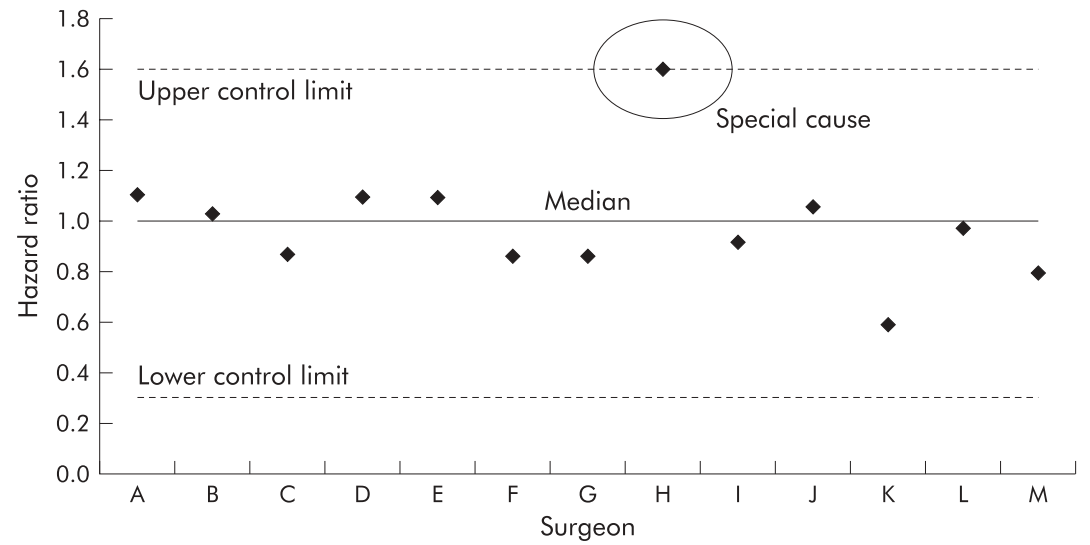

Figure 2 Control chart of surgeon specific hazard ratios.

fundamentally the underlying process of colorectal cancer care-for example, introduce colorectal cancer screening. In contrast, surgeon $\mathrm{H}^{\prime} \mathrm{s}$ mortality rate is consistent with special cause variation. This should be investigated, the special causes identified according to a predefined search strategy (such as the pyramid model of investigation ${ }^{4}$ ) and, if possible, eliminated.

FEATURES OF A CONTROL CHART The simplicity of the control chart has inevitably led to its widespread and successful application in manufacturing and service industries. ${ }^{6}$ However, behind this apparent simplicity underlies some important concepts. For instance, the control chart retains the information in the data by plotting (with respect to order, where appropriate) on a graph and so enjoys the ease of communication associated with (good) graphs ${ }^{7}$ while incorporating statistical thinking. The control chart is a guide to continual action-for common and special cause variation. The control limits continually remind us that the major improvement gains lie in reducing common cause variation (fig 2). Furthermore, by allowing for the play of chance and not ranking the data, control charts overcome the fundamental limitations and negative consequences of league tables and comparison with standards. Perhaps its most fundamental advantage is that "... the control chart process takes us through the complete cycle of the scientific method where we develop theories based on data prior to testing them ... it is one of very few statistical methods that complete the hypothesis generation-hypothesis testing cycle of the scientific method, which is one reason for its popularity with practitioners. Practitioners have found that they learn new information from the charts, rather than just making a 'yes/no' decision." It thus generates the knowledge which is the key to improvement. Finally, the usefulness of the control chart is enhanced when it is integrated with other SPC tools/concepts such as causeeffect diagrams, Pareto charts, flow charts, and operational definitions. ${ }^{69}$

\section{TRANSFER OF SPC TO HEALTH CARE}

Why then has SPC not been widely adopted in health care? Firstly, there is evidence that SPC is being increasingly applied in health care-for instance, a keyword literature search (using the term "statistical process control") of the Medline database found zero hits for 1951-88, two for 1989-91, 26 for 1992-5, and 71 for 1996-2004. In addition, a number of recent publications ${ }^{10-13}$ have reported the use of SPC in high profile cases such as the Bristol Inquiry and that of Dr Shipman, ${ }^{414}$ several health care specific SPC books have been published, ${ }^{15}$ and organisations such as the Joint Commission on Accreditation of Healthcare Organisations in the USA ${ }^{15}$ and the National Health Service Modernisation Agency in the UK have advocated its use. ${ }^{17}$ However, these are notable exceptions and not the rule.

In my view the reasons why SPC has been slow to transfer to health care include:

(1) SPC was first used in manufacturing industry so there is a reluctance, ${ }^{18}$ despite evidence to the contrary, ${ }^{4}{ }^{19}$ to accept that an approach for improving the quality of "widgets" can be legitimately applied to health care.

(2) Industry has a branch of statistics called industrial statistics (born, incidentally, from Shewhart's work $^{20}$ ); in health care we have medical statistics. Unfortunately, SPC does not feature in the most popular books on medical statistics.

(3) Ultimately, perhaps, the key constraint is that SPC is above all a way of thinking which challenges many of our fundamental assumptions about how to 


\section{EDITORIALS}

deliver improvement documented by Deming ${ }^{21}$-for example, management by objectives, futility of performance related pay, increased quality means increased costs and less production, local optimisation results in global optimisation. This is where past attempts to introduce SPC into health care have failed-not on the statistical arguments but on our reluctance to face the challenges that SPC makes to our overall management approach. For example: "In Australia in the early 1980s, hospital 'reform' was in full swing under the influence of a managerialist management system obsessed with very short term financial objectives and individual performance. The system was one of reducing costs in the short term and judging individuals, not of providing a quality service. SPC was bound to fail." 22

\section{CONCLUSION}

If we are to be more successful at continuous improvement in health care we must recognise that it embodies a science $^{23}$ encompassing a range of disciplines from SPC to human psychology. Given that the majority of our healthcare leaders and professionals have not been exposed to this science, we must address this deficiency through widespread education and training. One exemplar model of this is the Veterans Administration (VA) National Quality Scholars Fellowship Program (VAQS) in the USA. ${ }^{24}$ This is a two year postgraduate fellowship programme (primarily aimed at physicians) which seeks to develop leaders who will apply and develop the science of improvement. Incidentally, the core curriculum draws on the work of Shewhart and Deming. Perhaps the VA has been foremost in realising that, for health care continually to improve: "it is not enough to do your best; you must know what to do and then do your best." 25

Qual Saf Health Care 2004;13:243-245.

doi: 10.1136/qshc.2004.011650

Correspondence to: $\operatorname{Dr} M$ A Mohammed, Department of Public Health and Epidemiology, University of Birmingham, Birmingham B15

2TT, UK; m.a.mohammed@bham.ac.uk

\section{REFERENCES}

1 McArdle CS, Hole D. Impact of variability among surgeons on postoperative morbidity and mortality and ultimate survival. BMJ 1991;302:1501-5.

2 American Society for Quality. http:// www.asq.org/about/ history/shewhart, html. 2000 (accessed June 2004).

3 Shewhart WA. Economic control of quality of manufactured product. New York: D Van Nostrand Company, 1931 (reprinted by American Society for Quality Control, Milwaukee, Wisconsin, 1980)!

4 Mohammed MA, Cheng KK, Rouse A, et al. Bristol, Shipman, and clinical governance: Shewhart's forgotten lessons. Lancet 2001;357:463-7.

5 Mohammed MA, Rathbone A, Myers $P$, et al. An investigation into general practitioners associated with high patient mortality flagged up by through the Shipman inquiry: retrospective analysis of routine data. BMJ 2004;328:1474-7.

6 Ryan TP. Statistical methods for quality improvement. 2nd ed. New York: John Wiley and

7 Cleveland WS. Visualizing data. Summit, NJ: Hobart Press, 1993.

8 Hoerl RW. Discussion. J Qual Technol 2000;32:351-5.

9 Wheeler DJ, Chambers DS. Understanding statistical process control, 2nd ed. Knoxville, TN: SPC Press, 1992.

10 Tekkis PP, McCulloch P, Steger AC, et al. Mortality control charts for comparing performance of surgical units: validation study using hospital mortality data. BMJ 2003;326:786.

11 Benneyan JC, Lloyd RC, Plsek PE. Statistical process control as a tool for research and healthcare improvement. Qual Saf Health Care 2003; 12:458-464.

12 Adab P, Rouse AM, Mohammed MA, et al. Performance league tables: the NHS deserves better. BMJ 2002;324:95-8.

13 Spiegelhalter D, Grigg O, Kinsman R, et al. Risk-adjusted sequential probability ratio tests (SPRTs): applications to Bristol, Shipman and adult cardiac surgery. Int I Qual Health Care 2003; 15:7-13.

14 Aylin P, Best N, Bottle A, et al. Following Shipman: a pilot system for monitoring mortality rates in primary care. Lancet 2003;362:485-91.

15 Kelly DL. How to use control charts for healthcare. American Society for Quality. Wisconsin, USA: Quality Press, 1999.

16 Carey RG. Improving healthcare with control charts. Basic and advanced SPC methods and case studies. American Society for Quality. Wisconsin, USA: Quality Press, 2003.

17 NHS Modernisation Agency. Real measurement for real improvement using statistical process control. Innovation and Knowledge Group, http://www.modern.nhs.uk/search/ (accessed June 2004).

18 Wilson T, Holt T, Greenhalgh T. Use of Shewhart's technique (letter). Lancet 2001;357:1528-9.

19 Laffel G, Blumenthal D. The case for using industrial quality management in health care organizations. JAMA 1989;262:2869-73.

20 Pearson ES. A survey of the uses of statistical method in the control and standardization of the quality of manufactured products. J R Stat Soc 1933;96:21-75.

21 Deming WE. Out of the crisis. Massachusetts: Massachusetts Institute of Technology, 1986.

22 Morton AP. The use of statistical process control methods in monitoring clinical performance. Int $J$ Qual Health Care 2003;15:361-2.

23 Langley GJ, Nolan KM, Nolan TW, et al. The improvement guide, A practical approach to enhancing organisational performance. New York: Jossey-Bass, 1996.

24 Splaine ME, Aron DC, Dittus RS, et al. A curriculum for traning quality scholars to improve the health care of Veterans and the community at large. Qual Manage Health Care 2002;10:10-18.

25 Deming WE. http://www.brainyquote.com/ quotes/authors/w/w_edwards_deming.html (accessed June 2004). 